\title{
CONCEPÇÕES DE MEIO AMBIENTE ENTRE ESTUDANTES DE LICENCIATURA EM CIÊNCIAS BIOLÓGICAS
}

\author{
Fernanda de Almeida Cardoso ${ }^{1}$ \\ Rita de Cássia Frenedozo ${ }^{2}$ \\ Mauro Sérgio Teixeira de Araújo $^{3}$
}

Resumo: Visando analisar as concepções de Meio Ambiente (MA) dos estudantes do $1^{0}$ e $3^{\circ}$ anos do curso de licenciatura de Biologia em uma instituição de ensino particular foi aplicado um questionário para comparar o conhecimento prévio e adquirido sobre o tema. As concepções foram classificadas e mostram que entre alunos ingressantes predomina uma visão romântica do MA e que ela é alterada no decorrer do curso. Houve mudança na concepção socioambiental, sugerindo que os formandos desenvolvem maior consciência de que fazem parte do MA e se sentem responsáveis pela sua degradação, possivelmente pela sua maior maturidade e experiência social e acadêmica. A percepção reducionista permaneceu semelhante entre ingressantes e formandos, sinalizando que ainda acreditam que o MA se refere apenas à fauna e flora, fatores bióticos e abióticos e se excluem como seres pertencentes à natureza. Outros resultados sugerem que a Educação Ambiental não é realizada de maneira interdisciplinar, sendo considerados apenas temas biológicos, apontando para a necessidade de serem buscados outros encaminhamentos metodológicos no processo formativo dos estudantes.

Palavras-chave: Educação Ambiental; Percepção Ambiental; Ciências Biológicas.

\footnotetext{
${ }^{1}$ Universidade Cruzeiro do Sul, São Paulo - SP. E-mail: fernanda.de.almeida.cardoso@santander.com.br.

${ }^{2}$ Universidade Cruzeiro do Sul, São Paulo - SP. E-mail: rita.frenedozo@cruzeirodosul.edu.br.

${ }^{3}$ Universidade Cruzeiro do Sul, São Paulo - SP. E-mail: mstaraujo@uol.com.br.
} 


\section{Introdução}

Ao longo dos anos o homem desenvolveu uma visão distorcida e centralizada do ser humano em relação ao meio ambiente, ou seja, de forma cultural, a cada geração foi ensinado que tudo foi criado expressamente para nos servir, dando à natureza um valor somente de uso, ocasionando, em consequência, uma grande degradação ambiental e a utilização dos recursos naturais de forma insustentável (ROSA; SILVA, 2002; CAPRA, 1996a).

Depois do domínio sobre a agricultura, o homem passou a ser o único animal capaz de ser quase independente da natureza (BRANCO 1997c). Dizemos quase, porque o ecossistema urbano não é cíclico e autônomo como os outros, visto que os materiais são retirados do ambiente natural e depois não são reciclados como nos outros ecossistemas. Assim, o ser humano ainda depende da integridade da natureza para sobreviver, embora ainda não tenha se dado conta disso.

O homem se preocupa somente com o desenvolvimento econômico sem se incomodar com outros seres vivos que desapareciam, com a qualidade ambiental em grandes cidades, crescimento populacional e esgotamento dos recursos naturais. Até bem pouco tempo, não se falava em desenvolvimento sustentável e sustentabilidade (JACOBI, 2005; BRANCO, 1997b). Branco (1997a) define desenvolvimento sustentável como "um desenvolvimento não predatório", onde uma região deve suprir suas necessidades sem desgaste natural, respeitando o tempo de renovação dos recursos. Assim, o ambiente é visto como algo utilitário para o homem.

Para que essa visão não sustentável em relação ao meio ambiente seja alterada é necessário mudar não somente a visão do homem, mas também seus valores, tornando-os menos antropocêntricos e mais ecocêntricos, valorizando todos os seres vivos como membros de comunidades ligadas ecologicamente e ausente de hierarquia (CAPRA, 1996a). Reigota (1995) aborda a mudança do pensamento social como uma utopia alcançável e cita que a melhor forma seria com a independência do cidadão em relação ao Estado e através da Educação Ambiental (EA). Em parte a independência dos cidadãos já é realidade, pessoas estão participando de ONGs de proteção ambiental e organizando movimentos em defesa do meio ambiente. De acordo com Capra (1996b), a visão que dominou a sociedade por um longo período está sendo revista e retrocedendo, ampliando a percepção ecológica do mundo como um todo integrado e que a espécie humana faz parte dos processos cíclicos da natureza.

Uma forma de inserir na sociedade o conceito correto sobre sustentabilidade e assim diminuir os impactos sobre meio ambiente é aumentar a participação ativa de pessoas nas práticas educativas (JACOBI, 2005). A EA depende da percepção do meio ambiente das pessoas envolvidas na prática pedagógica, porém há variadas definições e interpretações de meio ambiente (REIGOTA 1995). Sauvé (2004) também cita que o tipo de abordagem da EA 
dependerá do conceito de meio ambiente, da intenção central, dos principais enfoques e do modelo pedagógico utilizado.

Apesar de não ser exclusividade dos professores de Biologia e Ciências, a EA hoje predominam atuações desses profissionais, de modo que o presente trabalho tem como objetivo identificar as percepções de meio ambiente de estudantes de licenciatura do curso de Ciências Biológicas de uma Universidade particular de São Paulo. Como parte da metodologia empregada buscou-se coletar dados através de um questionário aplicado a alunos ingressantes e formandos a fim de compará-los e identificar as contribuições e o alcance do processo de formação oferecido a esses alunos. A importância dessa investigação se evidencia na medida em que como docentes esses profissionais de Biologia terão papel fundamental na EA oferecida a centenas de estudantes da Educação Básica.

\section{A formação adequada de professores: um desafio a ser enfrentado}

A formação de professores no Brasil está baseada na Lei de Diretrizes de Bases da Educação Nacional LDB de 1996 (MELO, LUZ, 2005), que regulariza e faz cumprir as necessidades do ensino brasileiro. Estes autores questionam qual seria a ideal formação do professor e concluem que a LDB não está de acordo com a realidade e há grande necessidade de mudanças da política nacional de formação dos professores, devendo levar em consideração a realidade atual e as modificações para o futuro.

Entretanto, no Brasil essa formação se tornou um problema ao invés da solução, pois se constata preparação pedagógica sem conteúdo técnico ou preparação técnica com deficiência na formação pedagógica (MELO, 2007). Muito se fala sobre a decadência da qualidade escolar e para reverter este quadro é preciso atentar para o fato de que o principal subsídio escolar continua sendo o professor, visto que ele é o mediador entre o conhecimento e os alunos. Como qualquer outro profissional, para exercer tal importante função ele deverá ter uma formação inicial adequada e que deve ser prosseguida com qualidade (MELO; FINCK, 2011).

Sabe-se que a formação do professor se dá por experiências pessoais (sociais e familiares) e saberes formais, ou seja, já desde seus primeiros anos o professor está adquirindo características que irá utilizar na sua vida profissional, vivências como o modo de lecionar de seus professores, conquistas, problemas e alegrias o formam como sujeito, influenciando no profissional professor (LAMONATO; GAMA, 2010). Também, a formação é um processo contínuo onde a pessoa constitui sua aprendizagem pessoal e profissional através de saberes, experiências e práticas (SANTOS 2004; GAMA 2007). As aprendizagens têm origem pessoal, profissional, institucional e social, e acontecem durante toda a vida do indivíduo e no caso dos professores, levam-se em conta também as políticas públicas e suas atividades docentes. Nesta mesma linha de raciocínio, Pacheco (2003) assevera que o 
plano curricular na formação de professores deve incluir desenvolvimento pessoal, social, cultural, científica, tecnológica, técnica, artística e práticas pedagógicas.

Pereira e colaboradores (2010) apontam que com a degradação ambiental é visível a necessidade da inclusão da EA na formação de professores. Reforça essa percepção a constatação de a maioria dos professores trabalha apenas com reciclagem de lixo, sinalizando que eles ainda têm uma visão de ecologismo, sem relacionar o meio ambiente com o homem. Complementarmente, Taglieber (2004) afirma que as instituições educacionais estão encontrando dificuldade em incluir a EA no currículo de formação de professores e sugere como solução a formação continuada e a implantação de projetos de EA pelo governo articulados com universidades, escolas, secretarias de educação e agências formadoras.

\section{A Educação Ambiental e a legislação brasileira}

Apesar de a EA ser exigida pela Constituição Federal ainda não é aceita e executada conforme desejado, pois sugere ofensivas mobilizações para melhoria ambiental, sendo destacado que "quando bem realizada, a $E A$ leva a mudanças de comportamento pessoal e a atitudes e valores de cidadania que podem ter importantes consequências sociais" (BRASIL, 2010, p.182). Porém, se não houver uma EA de qualidade, as pessoas podem adquirir, devido à veiculação das informações distorcidas pela mídia, preconceitos em relação ao meio ambiente, acreditando que os ambientes naturais são intocáveis. Assim, as pessoas seriam levadas a crer que questões políticas, sociais, culturais não são de alçada dos ambientalistas, ou então que defensores do meio ambiente são pessoas que não precisam trabalhar, são radicais, defendem ideias que atrapalham quem realmente produz, pois defender animais seria incorreto enquanto há milhões de crianças morrendo. Essas visões não condizem com os princípios da EA (BRASIL, 2010), que defendem princípios como a importância de se considerar o ambiente como um todo integrado, envolvendo animais, plantas, itens abióticos, a cultura do ser humano, os valores éticos, políticos, a economia entre outros.

Outros princípios emanados pelos PCN sobre meio ambiente (BRASIL, 2010) são o processo contínuo e permanente tanto formal como informal, de modo que a EA deve começar em casa, ser desenvolvida na escola, dentro de empresas e em qualquer outro lugar onde houver pessoas; a perspectiva interdisciplinar da EA; o meio ambiente local, regional e nacional deve ser analisado; as experiências do passado devem ser levadas em consideração; bem como a complexidade dos problemas ambientais e a necessidade de se desenvolver o senso crítico e habilidades para reduzir, solucionar ou prevenir tais problemas, entre outros. Além dos expostos anteriores, uma das finalidades da EA é introduzir novos comportamentos de respeito à natureza nos indivíduos (DIAS, 2000b, p.109-110). Ainda, as práticas docentes em 
relação à $E A$ devem se basear na mudança de hábitos, atitudes e participação dos educandos, de forma que eles sejam encaminhados a refletir sobre os riscos produzidos pela humanidade buscando alternativas para a problemática (JACOBI, 2005). Nesse sentido, o papel do professor é fundamental para incitar uma educação compromissada com o desenvolvimento sustentável.

Ruscheinsky (2002) utiliza o termo "ecopedagogia" e propõe que a consciência ecológica deve partir de uma mudança cultural, indo além de projetos de despoluição ou preservação, criando uma cultura de desenvolvimento sustentável envolvendo a escola e toda a sociedade levando em consideração a ética ambiental. Não há perspectiva de uma mudança cultural considerável se a EA continuar apenas se baseando em coleta seletiva, coleta de resíduos, projetos de saneamento etc. É preciso enfatizar que a sociedade deve parar com seu consumo desenfreado e reduzir os volumes de resíduos produzidos e, uma vez produzidos e consumidos, efetuar o descarte correto.

Tendo em vista a importância da formação de quadros qualificados para fomentarem a EA em diferentes contextos, encontramos ressonância com esta investigação o que aponta o artigo 8ำ da referida legislação, visto que esta cita que as atividades ali apontadas devem ser devolvidas com capacitação de pessoas, desenvolvendo pesquisas e estudos, produzindo e divulgando materiais educativos e fazendo acompanhamento e avaliação (DIAS, 2000c). Além disso, é defendida explicitamente que "a dimensão ambiental deve constar dos currículos de formação de professores, em todos os níveis e em todas as disciplinas" e no seu parágrafo único fala que os professores já em atividade, devem ter seus currículos atualizados em relação ao tema (DIAS, 2000c, p.204). Como é possível perceber, ainda são necessárias muitas adequações no sistema educacional para que se alcancem os princípios da Política Nacional de Educação Ambiental, sendo importante que todos se engajem nesta frente de atuação e realizem pesquisas que favoreçam a efetivação dos pontos previstos na legislação aqui discutida.

\section{Percepções de meio ambiente entre alunos de Biologia}

Toda forma de conhecimento é uma construção social e histórica e a percepção do meio ambiente não poderia ser diferente. As diversas fontes de informação como livros, músicas, mídia e a vivência pessoal, podem levar a diferentes concepções de meio ambiente. Baseando-se nas representações de meio ambiente de professores, é possível distinguir suas práticas docentes sobre EA (REIGOTA, 1995; SAUVÉ 2003; REIGOTA, 1991). Neste sentido, Bezerra e Gonçalves (2007) afirmam que se a representação de meio ambiente do professor for a natureza que deve ser apreciada e respeitada, a metodologia usada será de envolvimento com o ambiente natural. Por outro lado, se for encarado como um problema, a metodologia será voltada para práticas buscando resolução desses problemas. 
As diversas definições de meio ambiente são incompletas e Reigota (1995) o define como:

O lugar determinado ou percebido, onde os elementos naturais e sociais estão em relações dinâmicas e em interação. Essas relações implicam processos de criação cultural e tecnológica e processos históricos e sociais de transformação do meio natural e construído. (REIGOTA, 1995, p.14).

Segundo o autor esta definição de meio ambiente é um espaço determinado no tempo e que é percebido, pois cada pessoa tem suas representações do meio.

\section{Procedimentos da pesquisa}

Como parte dos procedimentos que embasam esta investigação foram analisadas diversas obras de teóricos e pesquisadores que abordam as percepções de meio ambiente de diversos públicos e envolvem diferentes temas sobre Educação Ambiental (RODRIGUES; MALAFAIA, 2009; MARTINHO; TALAMONI, 2007; NERO, 2009, ROSA; SILVA, 2002; CUNHA; ZENI, 2007; SAUVÉ, 2004; BEZERRA; GONÇALVES, 2007).

Diante dos diferentes tipos de categorias de percepção ambiental, que de alguma maneira se assemelham ou se complementam, a metodologia aqui empregada buscou apoio no trabalho de Rodrigues e Malafaia (2009), pois nele as subdivisões de categorias de percepções ambientais são mais específicas, sendo possível, dessa forma, classificar com mais precisão as concepções dos alunos participantes da investigação. Para estes autores, as percepções sobre o meio ambiente se dividem em romântica, utilitarista, científica, abrangente, reducionista e sócio ambiental, que estão resumidas na figura 1 , sendo as mesmas definidas a seguir:

Reducionista - tem relação somente com os aspectos físicos naturais e exclui totalmente o homem e suas influências sobre o meio ambiente, pessoas com esse tipo de percepção não se veem como parte integrante da natureza e a supervalorizam em relação aos humanos. Esse tipo de percepção geralmente é reforçado pelos livros didáticos.

Científica - nesta concepção a natureza é abordada como sendo uma máquina inteligente e infalível.

Romântica - enaltece a natureza, como um meio ambiente em equilíbrio e belo, como se o homem não fizesse parte, está associada à preservação da natureza, não existindo degradação ambiental ou luta pela sobrevivência, é geralmente influenciada pela mídia e pelos livros didáticos. 
Socioambiental - reflete uma visão de natureza apropriada pelo homem, também está atrelada a esse tipo de concepção a degradação ambiental causada pelas ações humanas.

Utilitarista - é uma idealização da natureza como se tivesse sido criada apenas para servir o homem, os animais e plantas são considerados alimentos ou lazer para o ser humano, se há alguma intenção de preservação do meio ambiente, é para garantir que as próximas gerações possam usufruir.

Abrangente - é levado em consideração não apenas "os aspectos naturais, mas também os resultantes das atividades humanas, resultando na interação de fatores biológicos, físicos, econômicos e culturais", é um conceito que permite entender a complexidade das relações ambientais, não permanecendo somente nas dimensões ecológicas.

\begin{tabular}{|c|c|}
\hline Categorias & Descrição \\
\hline Romântica & $\begin{array}{l}\text { Elabora uma visão de "super-natureza", mãe natureza. Aponta a } \\
\text { grandiosidade da natureza, sempre harmônica, enaltecida, maravilhosa, com } \\
\text { equilíbrio e beleza estética. O homem não está inserido nesse processo. } \\
\text { Dentro dessa concepção está embutida uma visão dualística, homem vs. } \\
\text { natureza. }\end{array}$ \\
\hline Utilitarista & $\begin{array}{l}\text { Esta postura, também dualística, interpreta a natureza como fornecedora de } \\
\text { vida ao homem, entendendo-a como fonte de recursos para o homem. } \\
\text { Apresenta uma leitura antropocêntrica. }\end{array}$ \\
\hline Científica & $\begin{array}{l}\text { A natureza é abordada como máquina inteligente e infalível, dotada de um } \\
\text { conjunto de instrumentos essenciais e eficientes como a chuva, o sol, filtros } \\
\text { antipoluentes, umidade, evaporação, oxigenação e preservação. }\end{array}$ \\
\hline Abrangente & $\begin{array}{l}\text { Define o meio ambiente de uma forma mais ampla e complexa. Abrange uma } \\
\text { totalidade que inclui os aspectos naturais e os resultantes das atividades } \\
\text { humanas, sendo assim o resultado da interação de fatores biológicos, físicos, } \\
\text { econômicos e culturais. }\end{array}$ \\
\hline Reducionista & $\begin{array}{l}\text { Traz a ideia de que o meio ambiente refere-se estritamente aos aspectos } \\
\text { físicos naturais, como a água, o ar, o solo, as rochas, a fauna e a flora, } \\
\text { excluindo o ser humano e todas as suas produções. Diferentemente da } \\
\text { categoria "romântica", não proclama o enaltecimento da natureza. }\end{array}$ \\
\hline Socioambiental & $\begin{array}{l}\text { Desenvolve uma abordagem histórico-cultural. Essa leitura apresenta o } \\
\text { homem e a paisagem construída como elementos constitutivos da natureza. } \\
\text { Postula uma compreensão de que o homem apropria-se da natureza e que o } \\
\text { resultado dessa ação foi gerado e construído no processo histórico. Muitas } \\
\text { vezes o homem surge como destruidor e responsável pela degradação } \\
\text { ambiental. }\end{array}$ \\
\hline
\end{tabular}

Figura 1: Categorias representativas das concepções de meio ambiente.

Fonte: Rodrigues; Malafaia (2009).

A coleta de dados foi realizada através de um questionário aplicado em setembro de 2012, no Campus São Miguel da Universidade Cruzeiro do Sul, localizada na zona leste da cidade de São Paulo. O questionário foi respondido por um total de 40 alunos matriculados no curso de licenciatura em Ciências Biológicas, sendo 2 no $1^{\circ}$ semestre e 12 no $2^{\circ}$, representando alunos 
ingressantes, e 10 no $5^{\circ}$ semestre e 16 no $6^{\circ}$, correspondendo aos formandos. A escolha do grau de escolaridade se justifica na medida em que de acordo com Reigota (1995) a EA é feita através da percepção de meio ambiente da pessoa envolvida nas práticas pedagógicas e como alunos de licenciatura, os licenciandos serão futuros professores.

O questionário (Apêndice I) aplicado é composto de três questões de múltipla escolha e quatro discursivas, onde as questões de múltipla escolha são direcionadas para caracterização do público alvo e o restante para análise da percepção ambiental. Não havia respostas certas ou erradas, apenas questões reflexivas onde o aluno poderia expressar sua opinião; para cada resposta foi identificada uma relação com a categoria mais representativa de meio ambiente, caracterizando a percepção de meio ambiente do aluno. $O$ contato com os alunos foi feito durante o intervalo entre as aulas e no horário de entrada, quando então o questionário era entregue e explicada a sua finalidade.

\section{Resultados e Discussão}

\section{Caracterização do público alvo}

Conforme mostra a Tabela 1, um total de 40 alunos matriculados no primeiro e último ano do curso de licenciatura de Ciências Biológicas foi investigado, tendo havido maior participação de alunos concluintes do curso.

Tabela 1: Número de alunos investigados por divisão de semestre em que estão matriculados.

\begin{tabular}{|ccc|}
\hline Semestre & № de alunos & \% de alunos \\
\hline $\mathbf{1}$ & 2 & 5 \\
\hline $\mathbf{2}$ & 12 & 30 \\
\hline $\mathbf{5}$ & 10 & 25 \\
\hline $\mathbf{6}$ & 16 & 40 \\
\hline Total & 40 & 100 \\
\hline
\end{tabular}

A Tabela 2 mostra que esses 40 alunos envolvidos nesta pesquisa apresentam idades que variam entre 15 e 45 anos, prevalecendo alunos mais jovens, ou seja, com idades inferiores a 25 anos.

Tabela 2: Faixa etária dos alunos do curso de ciências biológicas que investigados.

\begin{tabular}{|ccccc|}
\hline Idade & $\begin{array}{c}\text { No de alunos } \\
\text { Ingressantes }\end{array}$ & $\%$ & $\begin{array}{c}\text { No de alunos } \\
\text { Formandos }\end{array}$ & $\%$ \\
\hline $\mathbf{1 5}-\mathbf{2 0}$ & 10 & 71,5 & 5 & 19,2 \\
\hline $\mathbf{2 1}-\mathbf{2 5}$ & 2 & 14,3 & 12 & 46,2 \\
\hline $\mathbf{2 6}-\mathbf{3 0}$ & 1 & 7,1 & 2 & 7,7 \\
\hline $\mathbf{3 1 - 3 5}$ & 1 & 7,1 & 5 & 19,2 \\
\hline $\mathbf{3 6}-\mathbf{4 5}$ & 0 & 0 & 2 & 7,7 \\
\hline $\mathbf{4 5}-\mathbf{5 5}$ & 0 & 0 & 0 & 0 \\
\hline
\end{tabular}

Revbea, São Paulo, V.10, № 2: 95-112, 2015. 
Para responder a questão de número três (outras formas de contato com o tema meio ambiente), o aluno poderia assinalar mais de uma opção e o resultado é apresentado na Tabela 3. Nessa questão, o aluno também poderia apontar a opção outros e exemplificar. Eles descreveram como outros: local de trabalho ou estágio, artigos, normas, leis, cursos extracurriculares, livros e pesquisa para o trabalho de conclusão de curso. Apenas $3,2 \%$ dos alunos ingressantes marcou a opção outros, esse baixo índice pode ser devido a estarem no início da vida acadêmica e por isso ainda não tiveram interesse, tempo hábil ou ainda não se sentem plenamente adaptados para realizarem atividades diversificadas do curso.

Tabela 3: Opções outros tipos de contato com o tema meio ambiente assinaladas pelos alunos.

\begin{tabular}{|c|cccc|}
\hline Tipo de contato & $\begin{array}{c}\text { No de Respostas } \\
\text { Ingressantes }\end{array}$ & $\%$ & $\begin{array}{c}\text { № de } \\
\text { Respostas } \\
\text { Formandos }\end{array}$ & $\%$ \\
\hline $\begin{array}{c}\text { Veículos de } \\
\text { comunicação }\end{array}$ & 13 & 41,9 & 23 & 35,4 \\
\hline $\begin{array}{c}\text { Escola básica } \\
\text { Palestras }\end{array}$ & 11 & 35,5 & 11 & 16,9 \\
\hline Família & 3 & 9,7 & 17 & 26,2 \\
\hline Outros & 3 & 9,7 & 5 & 7,7 \\
\hline $\begin{array}{c}\text { Nunca ouviu } \\
\text { falar }\end{array}$ & 0 & 3,2 & 9 & 0 \\
\hline Total & $\mathbf{3 1}$ & 0 & $\mathbf{6 5}$ & $\mathbf{1 0 0}$ \\
\hline
\end{tabular}

Cabe destacar que as questões de 4 a 8 do questionário foram analisadas e utilizadas para definir a concepção de meio ambiente dos alunos.

\section{Análise das concepções de meio ambiente dos alunos}

A Tabela 4 mostra que há nítidas diferenças entre a percepção dos alunos ingressantes no curso de Ciências Biológicas e a dos alunos formandos. Questionados sobre o que entendem por meio ambiente, nenhum aluno do último ano se enquadrou na categoria "romântica" e $21,4 \%$ dos alunos ingressantes se enquadra nessa categoria, sugerindo que com conhecimentos adquiridos no curso, houve mudança de concepção ambiental. Esta concepção de meio ambiente aponta para uma visão da natureza intocável, sempre harmônica e em perfeito equilíbrio, onde o homem está excluído.

Todos os alunos ingressantes enquadrados na categoria "romântica" têm idade entre 15 e 20 anos e indicaram que tiveram contato com o tema ambiental por meio de veículos de comunicação e na escola. Acreditamos que 
esta percepção romântica do meio ambiente está relacionada ao fato desses alunos terem saído recentemente do Ensino Médio, onde são utilizados livros didáticos que geralmente trazem imagens lindas da natureza sem mostrar a integração do homem a ela, o que pode ser reforçado ainda pela própria percepção de meio ambiente dos docentes. Algumas frases utilizadas pelos alunos enquadrados na categoria romântica para responder a pergunta de número 4 do questionário são reproduzidas a seguir:

(...) entende-se pela natureza de forma mais pura, local onde a vida pode ocorrer seguindo uma cadeia equilibrada.

Um meio natural que não tenha sido tocado pelo ser humano.

Um meio onde não teve a interferência humana.

Tabela 4: Concepções de meio ambiente percebidas por alunos ingressantes e formandos do curso de Biologia.

\begin{tabular}{|ccccc|}
\hline $\begin{array}{c}\text { Concepção de } \\
\text { Meio Ambiente }\end{array}$ & $\begin{array}{c}\text { No de } \\
\text { Respostas } \\
\text { Ingressantes }\end{array}$ & \% & $\begin{array}{c}\text { № de } \\
\text { Respostas } \\
\text { Formandos }\end{array}$ & $\%$ \\
\hline Socioambiental & 2 & 14,4 & 13 & 50 \\
\hline Reducionista & 3 & 21,4 & 8 & 30,8 \\
\hline Abrangente & 3 & 21,4 & 3 & 11,5 \\
\hline Utilitarista & 3 & 21,4 & 2 & 7,7 \\
\hline Romântica & 3 & 21,4 & 0 & 0 \\
\hline Científica & 0 & 0 & 0 & 0 \\
\hline Total & $\mathbf{1 4}$ & $\mathbf{1 0 0}$ & $\mathbf{2 6}$ & $\mathbf{1 0 0}$ \\
\hline
\end{tabular}

Ainda analisando os dados mostrados na Tabela 4 é possível perceber uma grande diferença entre os índices da categoria de percepção ambiental "socioambiental", pois enquanto $50 \%$ dos alunos formandos apresentam essa percepção, apenas $14,3 \%$ dos ingressantes foram enquadrados nessa categoria, na qual o ser humano se vê como responsável pela degradação ambiental, o meio ambiente é visto como uma apropriação da natureza pelo homem e nota-se a ocupação do meio ambiente pelo ser humano.

É possível que essa expressiva diferença decorra da maior maturidade dos alunos, por apresentarem maiores experiências pessoais e acadêmicas, já tomaram maior consciência que a responsabilidade pela degradação do meio ambiente é do homem, que contribuem para tal degradação e precisam tomar alguma atitude para reverter os problemas que afetam o meio onde vivem. Algumas frases dos alunos formandos identificados na concepção socioambiental são:

original.

O lugar onde vivemos, sendo este uma alteração da natureza 
É o meio em que vivemos, pode ser urbano, rural...

É todo o meio em que nós seres vivos habitamos.

Meio Ambiente seria o local onde vivemos e como podemos cuidar desse bem imensurável. tomando conta dele.

É o meio em que vivemos, e que infelizmente não estamos

A categoria "reducionista" refere-se ao meio ambiente somente nos aspectos físicos naturais, excluindo totalmente o ser humano, que é deixado como um elemento à parte, que não tem responsabilidade direta sobre conservação ou extinção dos ecossistemas. Esperava-se uma diminuição no índice dessa categoria, pois é de se imaginar que com o conhecimento adquirido no curso os alunos passassem a perceber que fazem parte da ecologia e que são responsáveis pela conservação ou destruição do meio, entretanto o índice para os alunos ingressantes foi de $21,4 \%$ e para os alunos formandos $30,8 \%$, sendo que estes utilizaram frases para descreverem o meio ambiente de forma reducionista tais como:

Meio ambiente é o conjunto de fatores bióticos e abióticos. ambientais.

Espaço delimitante pela natura do qual ocorrem interações

É tudo relacionado à natureza, tudo relacionado biologicamente.

abióticos.

Meio que nos cerca e que compreende fatores bióticos e

É presumível que não tenha havido redução nesse item por interpretação do aluno em relação aos conteúdos ministrados em sala de aula, ou pela percepção dos próprios docentes em relação ao meio ambiente, ou ainda que os docentes presumam que os alunos venham da escola básica já com uma visão mais abrangente de meio ambiente e não há enfoque aprofundado sobre o assunto. Além disso, como na escola básica, nos cursos de graduação ainda a EA não se tornou interdisciplinar, geralmente sendo de responsabilidade apenas do professor de Ecologia.

$\mathrm{Na}$ Tabela 5 é possível analisar as percepções de meio ambiente dos alunos como um todo. Os resultados $(27,5 \%$ reducionista e $37,5 \%$ socioambiental) corroboram um estudo similar realizado por Rodrigues e Malafaia (2009) onde, entre outras séries de ensino, analisaram a percepção ambiental de alunos matriculados no Ensino Médio de uma escola particular e outra de uma escola pública. As concepções predominantes foram também reducionista e socioambiental. Os autores justificam esse resultado da categoria reducionista devido à percepção da maioria dos brasileiros, que se 
referem ao meio ambiente como sendo estritamente a natureza (fauna e flora sem incluir o homem). Também citam que os livros didáticos utilizados apresentam uma abordagem fragmentada sobre o assunto, permitindo que 0 aluno desenvolva uma visão reduzida.

Com relação à categoria socioambiental, Rodrigues e Malafaia (2009) descreve que esse tipo de percepção está atrelado à modernização associada ao homem, que é tido então como um destruidor do meio ambiente, imagem muito difundida atualmente. 
Tabela 5: Concepções percebidas de meio ambiente pelos alunos do curso de Biologia.

\begin{tabular}{|c|cc|}
\hline $\begin{array}{c}\text { Concepção de } \\
\text { Meio Ambiente }\end{array}$ & № de Respostas & $\%$ \\
\hline Socioambiental & 15 & 37,5 \\
\hline Reducionista & 11 & 27,5 \\
\hline Abrangente & 6 & 15,0 \\
\hline Utilitarista & 5 & 12,5 \\
\hline Romântica & 3 & 7,5 \\
\hline Científica & 0 & 0 \\
\hline Total & $\mathbf{1 4}$ & $\mathbf{1 0 0}$ \\
\hline
\end{tabular}

\section{Conclusões}

Conforme exemplificado por Reigota (1995), o termo meio ambiente é descrito por diferentes autores de diversas formas, permitindo distintas interpretações que geralmente estão relacionadas com a experiência vivida pelo indivíduo. Por meio da metodologia de investigação empregada, envolvendo uma coleta de dados apoiada em um questionário (Apêndice I) e a análise baseada nas categorias propostas no trabalho de Rodrigues e Malafaia (2009), foi possível perceber que ao longo do curso de Ciências Biológicas, dos anos de experiências pessoais e profissionais como estágio em parques, em instituições de preservação do meio ambiente, museus ou até mesmo em sala de aula acompanhados pelo professor titular, há uma clara mudança de concepção ambiental por parte dos estudantes investigados. Neste sentido, se no primeiro ano do curso os alunos participantes desta pesquisa ainda preservam predominantemente uma visão romântica da natureza, os alunos formandos apresentam uma maior consciência de que são parte do meio ambiente e, portanto, também responsáveis pela degradação ambiental.

Apesar da diminuição no índice da concepção romântica observada, foi verificado que ainda há alunos formandos com uma visão reduzida do meio ambiente e que não levam em consideração as relações entre o homem e o ambiente que o cerca.

Conforme demonstrado na Tabela 3, a maioria dos alunos formandos e ingressantes do curso de Biologia responderam que tiveram contato com o tema meio ambiente através de veículos de comunicação, o que pode justificar algumas percepções distorcidas acerca do meio ambiente. De acordo com Trigueiro et al. (2008, p. 76), o investimento em massa dos canais de televisão em programações relacionadas à abundância da natureza e a preservação do meio ambiente pode contribuir para uma percepção de que o meio ambiente engloba apenas a fauna e a flora.

Cabe destacar que não apenas os veículos de comunicação contribuem para disseminar concepções inadequadas de meio ambiente, visto que grande parte dos alunos respondeu que tiveram contato com o conceito de meio ambiente na educação básica (Tabela 3). Neste nível de escolarização muitas vezes os livros utilizados mostram fotos de uma natureza intocada e 
perfeita, o que pode levar os alunos a desenvolverem uma percepção "romântica" ou "reducionista" de meio ambiente.

Analisando os alunos como um todo, constatamos que os resultados obtidos foram semelhantes aos apontados em outros estudos realizados nessa área. Como exemplo, no trabalho de Rodrigues e Malafaia (2009) os autores compararam as percepções ambientais de alunos do ensino Técnico de Meio Ambiente do primeiro e segundo semestres e também constataram que no decorrer do curso a visão "romântica" sobre o meio ambiente foi reduzida, sendo que aproximadamente $11 \%$ dos alunos do primeiro semestre foram enquadrados nessa concepção, enquanto nenhum aluno do segundo semestre manteve essa forma de conceber o meio ambiente. Neste mesmo trabalho os autores compararam alunos de Ensino Médio de escolas particulares e públicas e seus resultados mostram padrões semelhantes de respostas em relação à investigação que realizamos, ou seja, em ambos se destaca uma visão "reducionista" e "socioambiental" que caracteriza a percepção dos estudantes investigados.

Esta predominância nas visões "reducionista" e "socioambiental" de meio ambiente identificada tanto no trabalho atual como no de Rodrigues e Malafaia (2009) sugere que um entendimento mais amplo e adequado sobre esta temática ainda não faz parte da vida acadêmica de nível médio e superior, visto que uma visão abrangente, que englobaria os problemas ambientais, sociais, políticos e econômicos ainda é reduzida. Este fato possibilita constatar que a Educação Ambiental ainda não é realizada de maneira suficientemente interdisciplinar, levando em consideração na maioria das vezes apenas os aspectos biológicos.

Os resultados do estudo aqui apresentado sugerem que as concepções de meio ambiente ainda estão distante do que preconizam os Parâmetros Curriculares Nacionais, demonstrando que há necessidade de se promover renovadas abordagens sobre o tema. Deste modo, considerando que tanto os alunos formandos como os alunos ingressantes do curso de Biologia analisados não possuem uma visão ampla e adequada sobre o meio ambiente, não considerando alguns aspectos relevantes citados anteriormente, acreditamos que novos encaminhamentos metodológicos devam ser implantados.

Nesta perspectiva de renovação e adequação dos procedimentos educacionais, o papel dos professores e educadores torna-se essencial para que ocorra uma efetiva transformação da visão sobre meio ambiente dos discentes e futuros profissionais da área. Entre outras possibilidades, acreditamos que deva haver um incentivo maior para a participação dos alunos em atividades extracurriculares que envolvam o tema, de modo que a Universidade deve proporcionar uma quantidade maior dessas atividades. Ao mesmo tempo, seria desejável que a Universidade impulsionasse a pesquisa sobre diversos temas correlatos, envolvendo atividades investigativas a serem desenvolvidas além do período das aulas, estimulando com isto a autonomia e 
a responsabilidade dos estudantes. Por sua vez, no âmbito do próprio espaço educacional, seria oportuno que ocorressem leituras de artigos científicos em sala de aula, despertando o interesse e abrindo caminho para a realização de profícuas discussões acerca dessas temáticas.

Longe de esgotar o tema, ao final deste trabalho queremos salientar que é imprescindível que sejam analisadas diferentes propostas metodológicas, devendo ser realizados novos estudos complementares e aprofundados com o intuito de investigar suas possíveis contribuições no sentido de promover um aperfeiçoamento das concepções discentes acerca das temáticas ambientais, ampliando, assim, o alcance da Educação Ambiental.

\section{Referências}

ARROYO, M.G. Reinventar e formar o profissional da educação básica. Educação em revista, n. 37, p. 7-32, 2003.

BRANCO, S.M. O que é ecologia? In: 0 Meio ambiente em debate. $26^{\circ}$ ed. São Paulo: Moderna, 1997. Capítulo 1, p 7-12. (a)

BRANCO, S.M. Os impactos ambientais. In: 0 Meio ambiente em debate. $26^{\circ}$ ed. São Paulo: Moderna, 1997. Capítulo 3, p 20-26. (b)

BRANCO, S M. Impactos sociais e culturais? In: 0 Meio ambiente em debate. $26^{\circ}$ ed. São Paulo: Moderna, 1997. Capítulo 12, p 87-92. (c)

BRASIL. Lei no 9.795 (1999). Política Nacional de Educação Ambiental. Brasília, DF: Congresso Nacional, 1999.

BRASIL. Parâmetros Curriculares Nacionais: Terceiro e quarto ciclos do Ensino Fundamental. $1998 . \quad$ Disponível em: $<$ http://portal.mec.gov.br/seb/arquivos/pdf/ciencias.pdf>. Acesso em: 25/03/2013.

BRASIL. Parâmetros Curriculares Nacionais: meio ambiente. 2010. Disponível em: <http://portal.mec.gov.br/seb/arquivos/pdf/meioambiente.pdf>. Acesso em: 02 set. 2012.

BEZERRA, T.M.O.; GONÇALVES, A.A.C. Concepções de meio ambiente e educação ambiental por professores da Escola Agrotécnica Federal de Vitória de Santo Antão - Pe. Biotemas, v. 20, n. 3, p. 115 - 125, 2007.

CAPRA, F. Ecologia profunda - Um novo paradigma. In: A Teia da Vida; uma nova compreensão científica dos sistemas vivos. São Paulo: Cultrix, 1996. Capítulo 1. (a)

CAPRA, F. Das partes para o todo. In: A Teia da Vida; uma nova compreensão científica dos sistemas vivos. São Paulo: Cultrix, 1996. Capítulo 2. (b)

CONSELHO NACIONAL DE EDUCAÇÃO. Institui diretrizes curriculares nacionais para a formação de professores da educação básica, em nível superior, curso de licenciatura, de graduação plena. Resolução $n^{0}$ 1, de 18/02/02. Diário Oficial da União, Brasília, 09 de abril de 2002. Seção 1, p 31. 
CUNHA, T.S.; ZENI, A.L.B. A representação social de meio ambiente para alunos de ciências e biologia: subsídio para atividades em educação ambiental. Revista Eletrônica do Mestrado em Educação Ambiental, v. 18, p. 151-162, 2007.

DIAS, G.F. Elementos da História da Educação Ambiental. In: Educação Ambiental: princípios e práticas. 6o edição. São Paulo: Editora Gaia, 2000. Capítulo 1, p 23-98. (a)

DIAS, G. F. Os grandes eventos sobre educação ambiental. In: Educação Ambiental: princípios e práticas. 6º edição. São Paulo: Editora Gaia, 2000. Capítulo 2, 101-195. (b)

DIAS, G.F. Política nacional de educação ambiental. In: Educação Ambiental: princípios e práticas. 6ํeㄹção. São Paulo: Editora Gaia, 2000. Capítulo 3, p 201 207. (c)

GAMA, R.P. Desenvolvimento profissional com apoio de grupos colaborativos: o caso de professores de matemática em início de carreira. 2007. 240 f. Tese (Doutorado em Educação Matemática) - Universidade Estadual de Campinas, Campinas.

JACOBI, P.R. Educação Ambiental: o desafio da construção de um pensamento crítico, complexo e reflexivo. Educação e Pesquisa, v. 31, n. 2, p. 233-250, 2005.

LAMONATO, M.; GAMA, R.P.O desenvolvimento profissional do professor que ensina matemática na educação infantil: da constituição de si à docência. 2010. Disponível em: $<$ http://www.anped.org.br/33encontro/app/webroot/files/file/Trabalhos\%20em\%20PDF/GT196917--Int.pdf>. Acesso em: 25 ago. 2012.

MARTINHO, L.R.; TALAMONI, J.L.B. Representações sobre meio ambiente de alunos da quarta série do ensino fundamental. Ciência \& Educação, v. 13, n. 1, p. 1-13, 2007.

MELO, G.N. Os investimentos na formação de professores. Pátio, n. 40, p. 21-22, 2007.

MELO, L.G.; FINCK, S.C.M. Formação docente e prática pedagógica dos professores de educação física: uma análise do contexto. In: 5o Congresso Nacional de Educação, 2011, Curitiba. Anais do 5o Congresso Nacional de Educação. Curitiba: UEPG, p. 4-15, 2011.

MELO, P.A.; LUZ, R.J.P. A formação docente no Brasil. Instituto internacional para a educação superior na América Latina e o Caribe. 2005. Disponível em: $<$ http://www.oei.es/docentes/info pais/informe formacion docente brasil iesalc.pdf $>$. Acesso em: 05 set. 2012.

NERO, F.G.D. Concepções dos discentes dos cursos de licenciatura sobre educação ambiental, sua responsabilidade social e o papel formativo da universidade. In: $7^{0}$ Encontro Nacional de Pesquisa em Educação em Ciências, 2009, Florianópolis. Anais do $7^{\circ}$ Encontro Nacional de Pesquisa em Educação em Ciências. Florianópolis: UNICSUL, p. 1-9, 2009.

PACHECO, J.A. Formação de professores (documento de discussão). 2003. Disponível em:

<http://webs.ie.uminho.pt/jpacheco/files/formacaoProfessores.pdf>. Acesso em 25 ago. 2012. 
PAQUAY, L.; PERRENOUD, P.; ALTET, M.; CHARLIER, E. O trabalho sobre o habitus na formação de professores: análise das práticas e tomada de consciência. In: Perrenoud, P. Formando professores profissionais: Quais estratégias? Quais competências? 2ํㅡ. ed. Porto Alegre: Artmed Editora, Capítulo 9, p 161-182, 2001.

PEREIRA, F.A.; GUIMARÃES, F.M.; SOUZA, A.; ROCHA, M.B. Formação de professores em educação ambiental. Ciências em Foco, v. 1, n. 3, p. 1-4, 2010.

REIGOTA, M. Meio ambiente e representação social. São Paulo: Cortez, 1995.

REIGOTA, M. O que é educação ambiental. São Paulo: Brasiliense, 1991.

ROCHA, J.A.M. Modelo de monografia e Trabalho de Conclusão de Curso (TCC). Disponível em: <http://meiradarocha.jor.br/news/tcc/files/2009/06/modelo tcc-2011-1123a.doc .zip >. Acesso em: 05 ago. 2012.

RODRIGUES, A.S.L.; MALAFAIA, G. O meio ambiente na concepção de discentes no município de Ouro Preto - MG. Revista de estudos ambientais, v. 11, n. 2, p. 44-58, 2009.

ROSA, L.G., SILVA, M.M.P. Percepção ambiental de educandos de uma escola do ensino fundamental. Anais do 6옹 Simpósio Ítalo Brasileiro de Engenharia Sanitária e Ambiental. São Paulo: UEPB, p. 3-4, 2002.

RUSCHEINSKY, A. Educação Ambiental: abordagens múltiplas. Porto Alegre: Artimed, 2002.

SAUVÉ, L. Educação Ambiental e Desenvolvimento Sustentável: Uma análise complexa. Revista de Educação Pública, v. 6, n. 10, 1997.

SAUVÉ, L. Una cartografía de corrientes em educación ambiental. 2004. Disponível

em: <http://xa.yimg.com/kg/groups/23733054/1737417874/name/corrientes+Lucie+Sauv\%C3\%A9+ educacio+ambiental.pdf>. Acesso em: 28 ago. 2012.

SOUZA, E. C. O conhecimento de si: narrativas do itinerário escolar e formação de professores. 2004. 442 f. Tese (Doutorado em Educação) Programa de Pósgraduação em Educação, Faculdade de Educação, Universidade Federal da Bahia, Salvador.

TAGLIEBER, J. E. Formação continuada de professores em educação ambiental: contribuições, obstáculos e desafios. Disponível em: $<$ http://www.anped.org.br/reunioes/30ra/trabalhos/GT22-3455--Int.pdf $>$. Acesso em: 01 set. 2012.

TRIGUEIRO, A.; SIRKIS, A.; CAMARGO, A.; MINC, C.; VIOLA, E.; FELDMANN, F.; ALMEIDA, F.; GABEIRA, F.; CAPRA, F.; GIL, G.; CÂMARA, I. G.; CARVALHO, J. C.; VEIGA, J. E.; GOLDEMBERG, J.; BOFF, L.; DUARTE, M.; NALINI, R.; BORN, R. H.; CRESPO, S.; BESSERMAN, S.; NOVAES, W. Meio ambiente no século 21. Coordenação de TRIGUEIRO, A. 50 edição. Campinas: Editora Autores Associados, 2008. 


\section{APÊNDICE I}

Questionário

1) Qual semestre do curso de Ciências Biológicas que cursa? 1ㅇ ( ); 2…( ); $5^{\circ}$. ( ); ; 6 . ( ); outro ( )

2) A sua idade está entre: ( ) 15 e 20 anos; ( ) 21 e 25 anos; ( ) 26 e 30 anos;

( ) 31 e 35 anos; ( ) 36 e 45 anos; ( ) 45 e 55 anos

3) Além do curso, qual outro contato você teve relacionado ao assunto "meio ambiente"?

( ) Palestras

( ) Veículos de comunicação (revistas, televisão, internet, rádio, jornais)

( ) Na escola básica

( ) Na família

( ) Nunca ouviu falar

( ) Outros. Quais?

4) O que você entende por meio ambiente?

5) Você se considera responsável por algum problema ambiental? Qual?

6) O que você entende por desenvolvimento sustentável?

7) Quais os principais problemas ambientais da sociedade atual?

8) Em sua opinião quem seria responsável pela degradação do ambiente? 